\title{
PENGATURAN TEKANAN UDARA MAIN NOZZLE PADA AJL TSUDAKOMA TYPE ZAX 9100 UNTUK BEBERAPA NOMOR BENANG CARDED
}

\author{
NOZZLE MAIN AIR PRESSURE SETTING ON AJL TSUDAKOMA TYPE \\ ZAX 9100 FOR SOME CARDED YARN NUMBERS \\ Pian Syarif Hidayat ${ }^{1}$, Sajinu AP. ${ }^{2}$ dan Roni Syahroni ${ }^{3}$ \\ 1. Mahasiswa program D IV Teknik Tekstil, Politeknik STTT, Bandung, \\ 40272, Indonesia \\ 2. Dosen Jurusan Teknik Tekstil,Politeknik STTT, Bandung, 40272 , \\ Indonesia \\ 3. Dosen Jurusan Teknik Tekstil,Politeknik STTT, Bandung, 40272, \\ Indonesia \\ E-mail, d371nu@yahoo.com
}

\begin{abstract}
ABSTRAK
$P T$ " $X$ " belum mempunyai standar tekanan udara untuk main nozzle pada masingmasing nomer benang cotton carded, dan juga pengaturan tekanan udara masih mengunakan prinsip trial and error. Dari masalah tersebut mendorong penulis untuk mengamati dan mencari tekanan udara yang optimum untuk beberapa nomer benang cotton carded, tujuanya agar dapat dijadikan acuan tekanan udara untuk proses produksi bagi perusahaan dengan weft trouble paling sedikit. Penelitian dilakukan dengan mencari tekanan udara yang optimum dari rentang tekanan 0,30 Mpa-0,39 Mpa. Tekanan yang diamati pada masing-masing main nozzle adalah 0,30 Mpa, 0,33 Mpa, 0,36 Mpa, 0,39 Mpa untuk nomer benang cotton carded Ne120, Ne130 dan Ne140 yang kemudian dilakukan perhitungan terhadap jumlah weft trouble per shift, tekanan udara yang menghasilkan weft trouble paling kecil bisa dijadikan acuan standar perusahaan di PT " $X$ ".

Hasil percobaan dilapangan, tekanan udara yang optimum untuk nomer banang Ne1 20 adalah sebesar 0,39 Mpa dengan weft troubel rata-rata 18 kali kejadian, sedangkan tekanan udara untuk Ne1 30 adalah sebesar 0,36 Mpa dengan kejadian weft trouble rata-rata adalah 39 kejadian dan tekanan udara untuk Ne1 40 adalah sebesar 0,33 Mpa dengan kejadian weft trouble rata-rata adalah 42 kali kejadian

Kata kunci: Tekanan udara, main nozzle, weft trouble
\end{abstract}




\begin{abstract}
$P T$ " $X$ " does not yet have a standard air pressure for the main nozzle on each cotton carded thread number, and also the air pressure regulation still uses the principle of trial and error. From these problems encourage the author to observe and find the optimum air pressure for some cotton carded yarn numbers, so that it can be used as a reference for air pressure for the production process for companies with the least weft trouble. The study was conducted by finding the optimum air pressure from the pressure range of $0.30 \mathrm{Mpa}-0.39 \mathrm{Mpa}$. The observed pressures at each main nozzle are 0.30 MPa, 0.33 MPa, 0.36 MPa, $0.39 \mathrm{MPa}$ for cotton carded yarn numbers $\mathrm{Ne}_{1} 20, \mathrm{Ne}_{1} 30$ and $\mathrm{Ne}_{1} 40$ which then calculate the amount of weft trouble per shift, air pressure that produces the smallest weft trouble can be used as a reference as a company standard at $P T$ " $X "$.

In the field results, the optimum air pressure for the number Ne1 20 is $0.39 \mathrm{MPa}$ with an average of 18 times weft troubles, while the optimum pressure for Ne1 30 is 0.36 MPa with an average weft trouble is 39 events and the air pressure for Ne1 40 is the optimum pressure is $0.33 \mathrm{MPa}$ with the average weft trouble occurrence is 42 times the event
\end{abstract}

Keywords: air pressure, main nozzle, weft trouble

\section{PENDAHULUAN}

PT " $X$ " masih belum memiliki standar pengaturan tekanan udara untuk main nozzle untuk beberapa nomer benang pakan. Besar kecilnya tekanan udara pada main nozzle peluncuran benang pakan harus diatur sesuai dengan bahan baku benang yang akan diproses pada saat proses penyisipan. Menurut Sabit adanur (2009), Benang- benang yang memiliki diameter besar memerlukan tekanan udara yang lebih besar untuk meluncurkanya. Massa benang meningkat seiring dengan meningkatnya diameter benang, luas permukaan benang meningkat seiring dengan diameternya (p. 207). Maka tekanan udara harus semakin besar, jika benang dengan diameter besar mengunakan tekanan udara yang terlalu kecil maka benang akan 
kekurangan daya dorong yang meyebabkan pakan tidak sampai (short pick). Begitu pun sebaliknya jika benang kecil mendapatkan tekanan udara yang besar maka akan meyebabkan pakan berlebih. Benang dengan diameter kecil harus mengunakan tekanan udara yang relatif lebih kecil untuk meluncurkanya karena massa benang relatif kecil.

Benang dengan diameter besar atau kecil jika pengaturan tekanan udaranya tidak tepat akan meyebabkan weft trouble baik short pick maupun long pick dimana mesin akan mati, akibat masalah tersebut akan mempengaruhi kelancaran mesin. Oleh sebab itu tekanan udara harus disesuaikan dengan diameter benang yang digunakan, dengan cara mencari tekanan udara yang optimum untuk masing-masing nomer benang pakan yang akan diproses di mesin, sehingga nantinya didapatkan standar tekanan udara optimum untuk masing-masing nomer benang pakan yang dapat digunakan oleh perusahaan yang memiliki weft trouble paling sedikit.

Penelitian ini dimaksudkan untuk menentukan tekanan udara main nozzle pada masing-masing nomer benang cotton carded pada proses pertenunan.

Sedangkan tujuan dari percobaan ini adalah mendapatkan tekanan udara yang optimum pada main nozzle untuk masing-masing nomor benang cotton carded yang dapat digunakan perusahaan yang memiliki weft trouble paling sedikit.

Peluncuran benang pakan pada mesin air jet loom disebut dengan proses filling insertions motion mengunakan sistem semprotan udara sebagi proses untuk penyisipan benang yang dibantu oleh main nozzle maupun sub nozzle. Fungsi main nozzle adalah untuk meningkatkan energi kinetik aliran udara dalam suatu proses penyisipan benang. Sedangkan fungsi sub nozzle yaitu membantu proses penyisipan benang pakan agar sampai di ujung kain. Pada mesin air jet loom pengaturan semprotan udara untuk proses penyisipan dapat diatur sesuai dengan kebutuhan. Pengaturan ini meyebabkan semprotan tekanan udara menjadi berlebih maupun tekanan udara menjadi berkurang. Kelebihan dan kekurangan tekanan udara pada saat peluncuran akan sangat berpengaruh pada proses penyisipannya. Peluncuran benang 
harus dilakukan dengan pengaturan tekanan udara yang optimum. Oleh sebab itu besarnya tekanan udara pada nozzle harus tepat, sesuai dengan kebutuhan yang digunakan.

Semakin besar $\mathrm{Ne} 1$ benang diameternya semakin kecil dan tipis, semakin kecil $\mathrm{Ne} 1$ benang diameternya semakin basar dan tebal. Kedua tipe benang ini membutuhkan pengaturan semprotan tekanan udara yang optimum sesuai dengan diameternya. Menurut Sabit Adanur (2009), untuk meningkatkan kecepatan benang, gaya gesek udara harus dinaikkan dan tegangan benang yang menghambat gerakan benang harus ditrurunkan (p.206). Maka untuk meningkatkan gaya gesek udara, kecepatan udara harus dinaikan. Besar kecilnya tekanan udara berhubungan dengan kecepatan, semakin besar tekanan maka semakin besar kecepatan proses penyisipannya. begitupun sebaliknya semakin rendah tekanan maka semakin lambat proses penyisipannya.

Besar kecilnya dimeter benang agar sampai di ujung kain dipengaruhi oleh besarnya tekanan udara. Pengaturan tekanan udara optimum pada benang dapat dilihat pada gambar 1 berikut

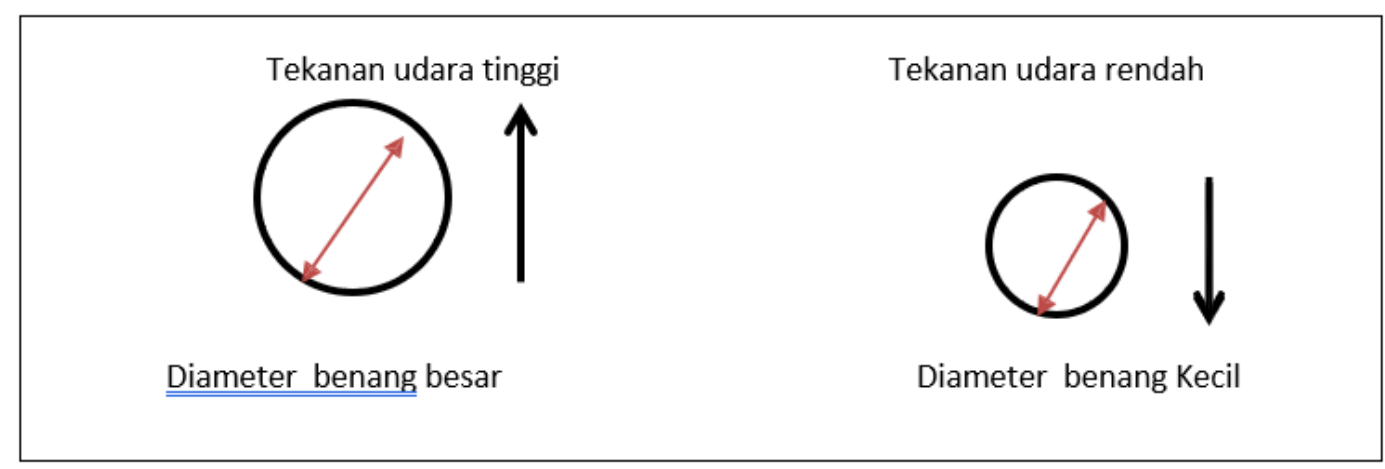

Gambar 1. Penampang Melintang Diameter Benang dengan Tinggi dan Rendahnya Tekanan Udara

Dari gambar diatas dapat dijelaskan bahwa benang dengan diameter besar harus mendapatkan udara yang besar, sedangkan benang dengan diameter kecil harus mendapatkan tekanan udara yang relatif lebih 
rendah. Hal ini dikarenakan benang dengan diameter besar ketika proses penyisipan benang pakan diameter besar akan didorong oleh tekanan udara pada permukaan kain yang menyebabkan pengaturan tekanan udaranya harus besar, jika mendapatkan tekanan terlalu rendah benang akan short pick (pakan tidak sampai). Sedangkan benang dengan diameter kecil harus mendapatkan udara yang relatif lebih rendah karena jika benang mendapatkan udara yang besar benang akan mengalami long pick (pakan berlebih).
Karena benang mengalami dorongan tekanan udara dari atas dan bawah dengan cara melingkupi permukaan benang dimana benang dengan diameter besar harus mendapatkan udara yang besar karena jika tidak mendapatkan tekanan udara yang sesuai untuk benang dengan diameter besar tidak akan sampai di ujung kain. Sedangkan benang dengan diameter kecil jika tekanan udara terlalu besar akan meyebabkan pakan berlebih tekanan udara harus relatif rebih rendah

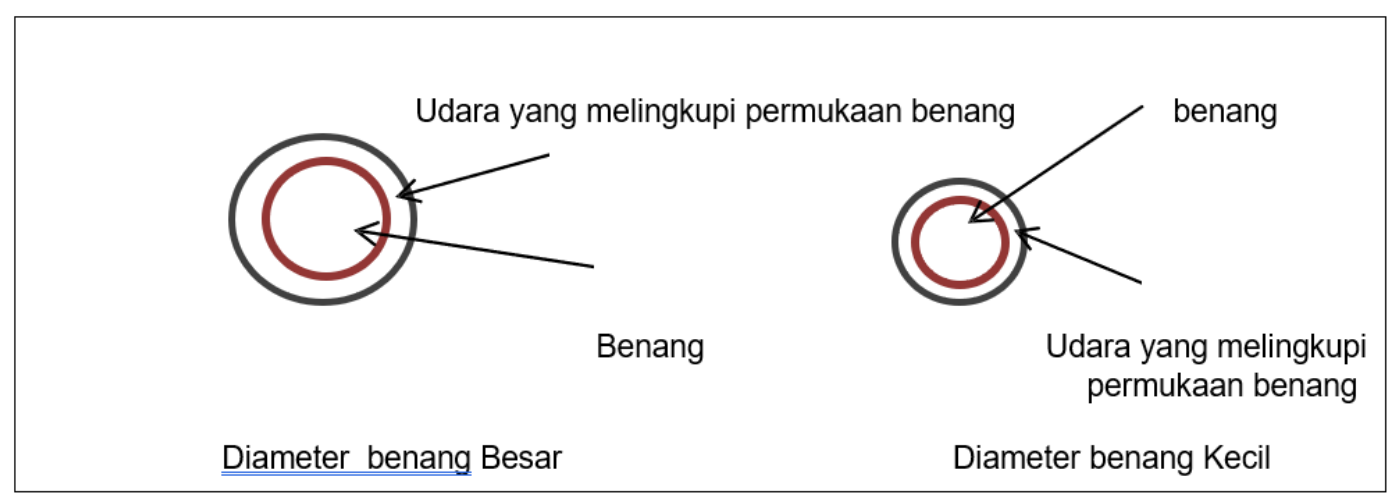

Gambar 2. Penampang Melintang Diameter Benang Dengan Tekanan Udara

\section{METODA PENELITIAN}

Penelitian ini dilakukakan dengan cara melakukan percobaaan beberapa variasi pengaturan tekanan udara main nozzle pada AJL Tsudakoma dan mengamati pengaruhnya terhadap kegagalan peluncuran pakan.
Peneitian dibatasi hanya melakukan percobaan variasi tekanan udara main nozzle sebanyak 4 stelan untuk tiga jenis nomor benang yang berbeda Penelitian ini dilakuakan di sebuah pabrik tekstil di daerah Surakarta pada tahun 2018. 


\section{Alat dan Bahan}

Mesin yang digunakan dalam penelitian ini adalah AJL Tsudakoma dengan spesifikasi sbb :

1. No mesin

2. Jenis Mesin

3. Merek Mesin

4. Tipe

5. Tahun

6. Negara pembuat

7. RPM

8. Efisiensi

9. Power/uni

10. Pembentuk Mulkut Lusi
: 159

: Air Jet Loom

: Tsudakoma

: ZAX 9100

: 2010

: Jepang

$: 780$

$: 70 \%$

$: 3 \mathrm{Kw}$

: Cam positive

Bahan atau kain yang dipakai dalam penelitian ini mempunyai spesifikasi sebagai beikut :

1. Kain

2. Kontruksi

3. Jenis lusi

4. Jumlah benang lusi

5. Tetal lusi

6. Tetal pakan

7. Lebar kain

8. Lebar sisir
: CDP 2040

: Anyaman plain

: $30 \mathrm{CD}$

: 5056 helai

: 67,16 helai / inc

: 68 helai / inc

: $191,0 \mathrm{~cm}$

: $203,6 \mathrm{~cm}$

Penyetelan tekanan udara yang tetap pada percobaan ini adalah :
1. Sub nozzle (S) $\quad: 0,43 \mathrm{Mpa}$
2. Jet flow (J1) : 0,09 Mpa
3. Jet Flow (J2) $\quad: 0,07 \mathrm{Mpa}$
4. Jet colour (C1) : 0,03 Mpa
5. Jet colour (C2) : 0,04 Mpa

Sedangkan penyetelan yang divariasikan adalah tekanan Main Nozzle : -

- Tekanan udara yang ke $1: 0,30 \mathrm{Mpa}$

- Tekanan udara yang ke $2 \quad: 0,33 \mathrm{Mpa}$

- Tekanan udara yang ke $3 \quad: 0,36 \mathrm{Mpa}$ 
- Tekanan udara yang ke 4 : 0,39 Mpa

\section{HASIL DAN PEMBAHASAN}

Hasil Pengujian Tekanan Udara Main Nozzle pada Nomer Benang Ne1 20

Tabel 1. Hasil Pengujian Weft Trouble pada Nomer Benang Ne1 20

\begin{tabular}{|c|c|c|c|c|}
\hline \multirow{2}{*}{ Parameter } & \multicolumn{3}{|c|}{ Tekanan udara main nozzle } \\
\cline { 2 - 5 } & $0,30 \mathrm{Mpa}$ & $0,33 \mathrm{Mpa}$ & $0,36 \mathrm{Mpa}$ & $0,39 \mathrm{MPa}$ \\
\hline Jumlah Jam (n) & 8 & 8 & 8 & 8 \\
\hline $\begin{array}{c}\text { Jumlah Weft } \\
\text { Trouble ( } \Sigma \text { ) }\end{array}$ & 93 & 64 & 21 & 18 \\
\hline Rata-rata $(x)$ & 11,62 & 8 & 2,62 & 2,25 \\
\hline SD & 1,05 & 0,75 & 0,74 & 0,7 \\
\hline CV & 9,03 & 9,37 & 28,24 & 31,11 \\
\hline
\end{tabular}

\section{Hasil Pengujian Tekanan Udara Main Nozzle Pada Nomer Benang Ne1 30}

Tabel 2. Hasil Pengujian Weft Trouble pada Nomer Benang Ne1 30

\begin{tabular}{|c|c|c|c|c|}
\hline \multirow{2}{*}{ Parameter } & \multicolumn{3}{|c|}{ Tekanan udara main nozzle } \\
\cline { 2 - 5 } & $0,30 \mathrm{Mpa}$ & $0,33 \mathrm{Mpa}$ & $0,36 \mathrm{Mpa}$ & $0,39 \mathrm{Mpa}$ \\
\hline \multirow{2}{*}{ Jumlah Jam (n) } & 8 & 8 & 8 & 8 \\
\hline $\begin{array}{c}\text { Jumlah Weft } \\
\text { Trouble }(\Sigma)\end{array}$ & 87 & 61 & 39 & 52 \\
\hline \multirow{2}{*}{ Rata-rata $(x)$} & 10,87 & 7,62 & 4,87 & 6,5 \\
\hline SD & 0,83 & 1,05 & 0,82 & 1,19 \\
\hline- & 7,63 & 13,77 & 16,83 & 18,3 \\
\hline CV & & & & \\
\hline
\end{tabular}


Hasil Pengujian Tekanan Udara Main Nozzle Pada Nomer Benang Ne1 40

Tabel 3. Hasil Pengujian Weft Trouble pada Nomer Benang Ne1 40

\begin{tabular}{|c|c|c|c|c|}
\hline \multirow{2}{*}{ Parameter } & \multicolumn{4}{|c|}{ Tekanan udara main nozzle } \\
\cline { 2 - 5 } & $0,30 \mathrm{Mpa}$ & $0,33 \mathrm{Mpa}$ & $0,36 \mathrm{Mpa}$ & $0,39 \mathrm{Mpa}$ \\
\hline Jumlah Jam (n) & 8 & 8 & 8 & 8 \\
\hline $\begin{array}{c}\text { Jumlah Weft } \\
\text { Trouble }(\Sigma)\end{array}$ & 84 & 42 & 57 & 68 \\
\hline Rata-rata $(x)$ & 10,5 & 5,25 & 7,12 & 8,5 \\
\hline SD & 0,75 & 0,96 & 0,98 & 1,92 \\
\hline CV & 7,14 & 18,28 & 13,76 & 22,5 \\
\hline
\end{tabular}

\subsection{Tekanan Udara Main nozzle Untuk Nomer Benang Ne1 20}

Dari hasil percobaan yang dilakukan didapatkan grafik hasil sebagai berikut :

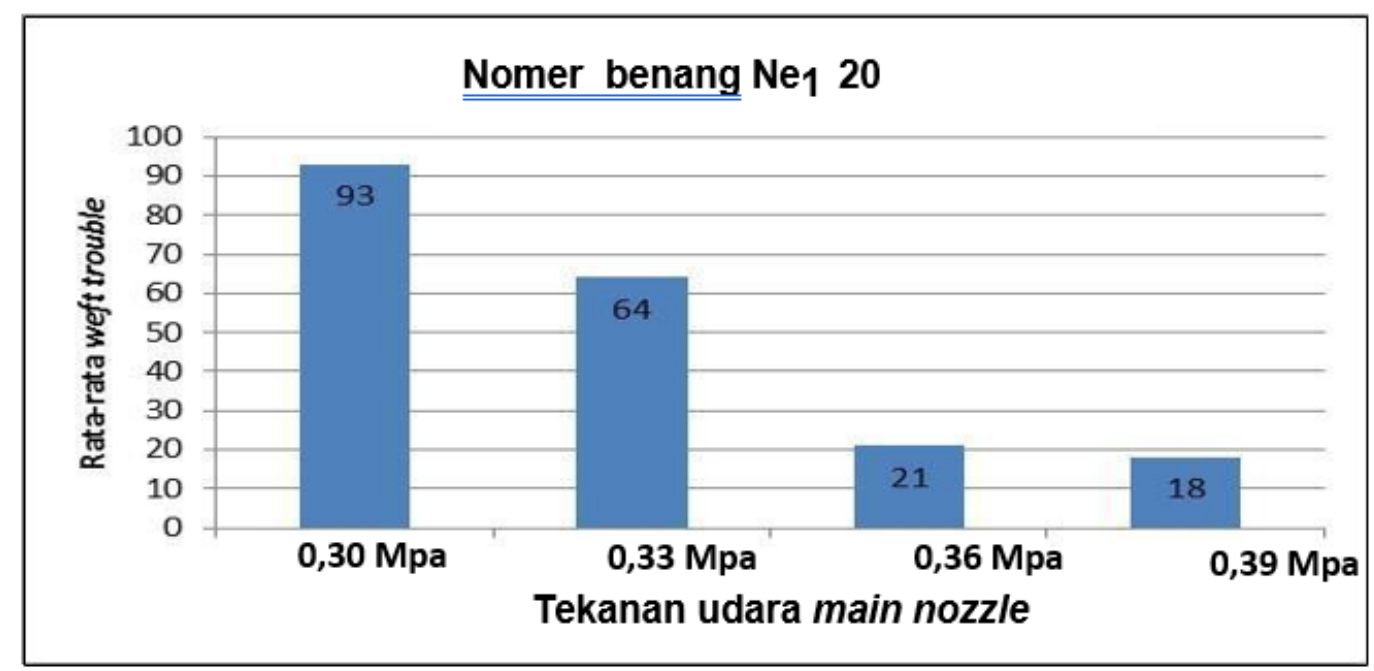

Gambar 3. Grafik Tekanan Udara Main Nozzle Terhadap Rata-ata Weft Trouble pada Nomer Benang $\mathrm{Ne}_{1} 20$

Dari gambar diatas dapat dijelaskan

yaitu sebagai berikut :
1. Tekanan main nozzle dengan tekanan 0,30 Mpa 
Pada tekanan ini dengan mengunakan nomer benang $\mathrm{Ne1}$ 20 dimana nomer benang $\mathrm{Ne} 120$ adalah nomer benang dengan diameter yang besar oleh sebab itu tekanan yang harus diberikan harus relatif besar sedangkan pada tekanan 0,30 Mpa tekanan masih relatif kurang hal ini dapat dilihat weft trouble yang terjadi adalah yang paling banyak bila dibandingkan dengan tekanan yang lain yaitu sekitar 93 kali kejadian selama satu shift hal ini karenakan tekanan terlalu kecil sedangkan nomer benang yang dipakai adalah nomer benang $\mathrm{Ne} 120$ dimana nomer benang $\mathrm{Ne} 120$ memiliki diameter besar oleh sebab itu tekanan 0,30 Mpa memiliki weft trouble yang relatif banyak bila dibandingkan dengan tekanan yang lain.

2. Tekanan main nozzle dengan tekanan 0,33 Mpa

Pada tekanan ini dangan mengunkan Ne1 20 dimana nomer benang dengan mengunakan tekanan 0,33 Mpa kejadian weft trouble adalah sekitar 64 kejadian dibandingkan dengan tekanan udara 0,30 Mpa kejadian weft trouble mengalami penurunan tetapi masih relatif besar dibandingkan dengan variasi tekanan yang lainnya. Hal ini dikarenakan tekanan 0,33 Mpa mengalami kenaikan sekitar 0,3 Mpa hal ini membuat benang pakan mengalami daya dorong tambahan yang membuat benang pakan sedikit mengalami penurunan masalah weft trouble dimana hanya 64 kejadian selama satu shift yang mengalami mati mesin karna weft trouble.

3. Tekanan main nozzle dengan tekanan 0,36 Mpa

Pada tekanan ini mengunakan nomer benang Ne1 20 dengan tekanan 0,36 Mpa dimana kejadian weft trouble mengalami penurunan hal ini karenakan benang pakan mengalami tambahan tekanan yaitu sekitar 0,3 Mpa dimana tekanan tambahan ini membantu benang pakan untuk sampai di ujung kain. Dari satu shift kejadian weft trouble dengan tekanan 0,36 Mpa yaitu sekitar 21 kejadian tetapi masih relatif lebih besar dibanding tekanan 0,39 Mpa, dari satu shift kejadian mati mesin karna weft trouble adalah 21 kejadian hal ini karena masa tekanan udara meningkat dan 
membuat benang sampai diujung kain.

4. Tekanan main nozzle dengan tekanan 0,39 Mpa

Pada tekanan 0,39 Mpa dengan mengunakan nomer benang $\mathrm{Ne} 1$ 20 dapat dilihat pada grafik mengalami penurunan dibandingkan dengan dengan variasi tekanan yang lain hal ini karena tekanan 0,39 Mpa dibanding tekanan yang lain memiliki daya dorong yang cukup pada benang $\mathrm{Ne} 120$ hal ini terlihat dimana weft trouble mengalami penurunan dibanding variasi tekanan sebelumnya dalam satu shift hanya sekitar 18 kali terjadi weft trouble

\subsection{Tekanan Udara Main nozzle untuk Nomer Benang Ne1 30}

Dari hasil percobaan yang dilakukan didapatkan grafik hasil sebagai berikut :

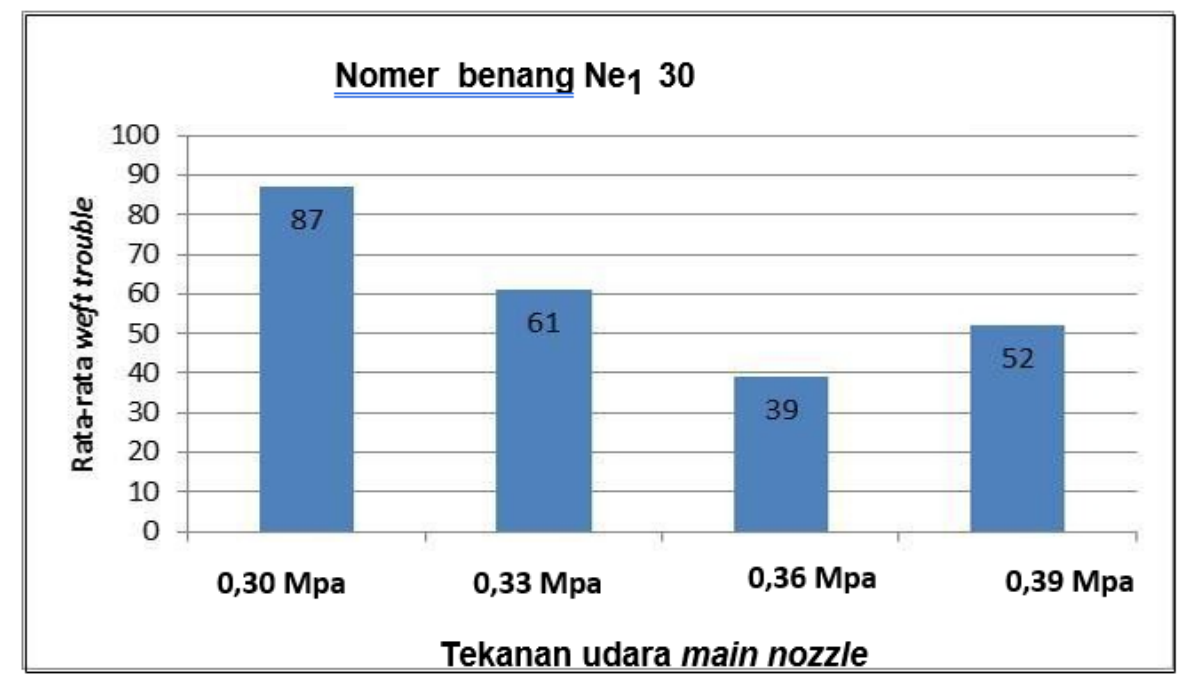

Gambar 4. Grafik Tekanan Udara Main Nozzle Terhadap Rata-ata Weft Trouble pada Nomer Benang Ne1 30

Dari gambar diatas dapat dijelaskan yaitu sebagai berikut :

1. Tekanan main nozzle dengan tekanan 0,30 Mpa.
Pada tekanan ini dapat dilihat dengan menggunakan nomer benang $\mathrm{Ne} 130$ weft trouble yang terjadi adalah sekitar 87 kejadian dimana hal ini dapat dijelaskan karena nomer benang $\mathrm{Ne} 130$ adalah 
nomer benang yang memiliki diameter yang sedang tekanan yang diberikan adalah sekitar 0,30 Mpa dimana tekanan ini sangat kecil dibandingkan dengan variasi tekanan yang lainnya. Oleh sebab itu pada saat benang disuapkan menggunakan tekanan ini benang mengalami kekurangan daya dorong pada main nozzle yang mengakibatkan mesin sering mati yang mengakibatkan weft trouble sekitar 87 kejadian.

\section{Tekanan main nozzle dengan tekanan 0,33 Mpa}

Pada tekanan ini dapat dilihat dengan menggunakan nomer benang $\mathrm{Ne} 130$ menggunakan tekanan $0,33 \mathrm{Mpa}$, tekanan mengalami kenaikkan sekitar 0,03 Mpa yang membuat mesin pada saat meyuapkan benang mengalami penurunan sekitar 61 kejadian hal ini bila dibandingkan dengan tekanan yang lainnya memiliki tekanan yang optimum karena weft trouble yang terjadi yang paling kecil bila dibandingkan variasi tekanan yang lain.

3. Tekanan main nozzle dengan tekanan 0,36 Mpa
Pada tekanan ini dapat dilihat benang yang digunakan adalah nomer benang $\mathrm{Ne}_{1} 30$ dengan tekanan sekitar 0,36 Mpa dimana memiliki kenaikkan sekitar 0,06Mpa. Dapat dijelaskan bahwa benang pakan yang yang disuapkan memiliki kejadian weft trouble yang cenderung meningkat hal ini dapat dilihat yaitu sekitar 39 kejadian hal ini bila dibandingkan dengan tekanan sebelumnya yaitu tekanan 0,33 Mpa, tekanan 0,36 Mpa benang pakan yang mengalami weft trouble mengalami penurunan dimana tekanan 0,36 terhadap nomer benang cotton $\mathrm{Ne}_{1} 30$ bila dibandingkan dengan tekanan udara yang lain.

4. Tekanan main nozzle dengan tekanan 0,39 Mpa

Pada tekanan ini pada grafik dapat dilihat bahwa benang yang digunakan adalah benang nomer benang $\mathrm{Ne} 130$ dengan tekanan 0,39 Mpa dimana tekanan mengalami kenaikan sekitar 0,09 Mpa. Dari hasil percobaan tekanan 0,39 $\mathrm{Mpa}$ mengalami wept trouble yang tinggi yaitu sekitar 52 kali kejadian weft troubel hal ini karena tekanan udara pada saat meyuapkan benang pakan 
terlalu besar hal ini menyebabkan mesin sering mati karena relatif terlalu besar dengan diameter benang pakan yang disuapkan yang meyebabkan benang keluar dari lintasan yang meyebabkan mesin mati, dimana tekanan terlalu besar mengakibatkan terjadinya fenomena turbulensi pada saat proses penyisipannya, bila dibandingkan dengan tekanan 0,36 tekanan 0,36 Mpa merupakan tekanan optimal dimana mesin hanya mengalami kejadian mati mesin karena weft troubel sekitar 39 kali kejadian, sedangkan tekanan 0,39 Mpa masih belum optimal karena weft troube/ relatif lebih besar dikarenakan tekanannya terlalu besar

\subsection{Tekanan Udara Main nozzle untuk Nomer Benang Ne1 40}

Dari hasil percobaan yang dilakukan didapatkan grafik hasil sebagai berikut :

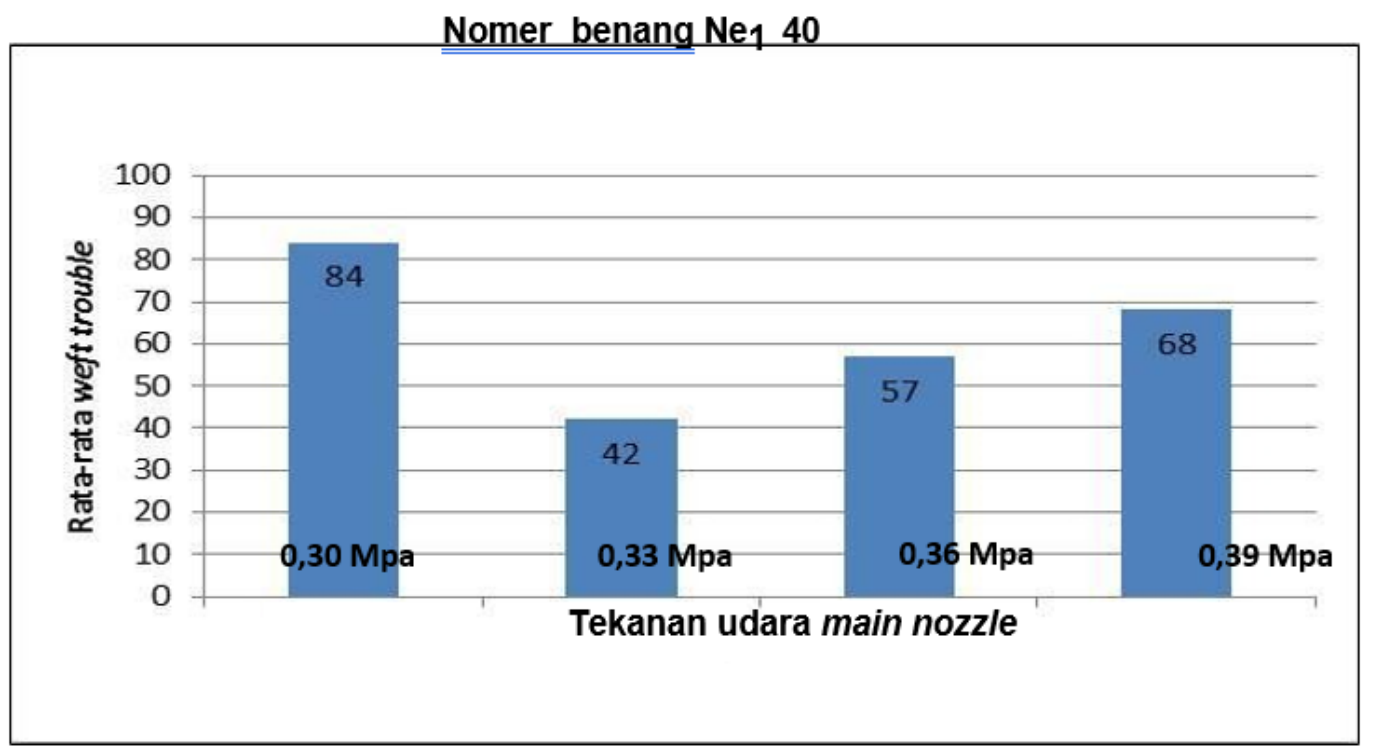

Gambar 5. Grafik Tekanan Udara Main Nozzle Terhadap Rata-ata Weft Trouble pada Nomer Benang $\mathrm{Ne}_{1} 40$

Dari gambar diatas dapat dijelaskan yaitu sebagai berikut :
1. Tekanan main nozzle dengan tekanan $0,30 \mathrm{Mpa}$ 
Pada tekanan ini dengan menggunakan nomer benang $\mathrm{Ne} 1$ 40 dimana benang nomer $\mathrm{Ne}_{1} 40$ adalah nomer benang yang memiliki diameter yang kecil pada percobaan diatas dapat dilihat tekanan menggunakan tekanan $0,30 \mathrm{Mpa}$ memiliki kejadian weft trouble sekitar 84 kejadian hal ini karena tekanan 0,30 Mpa terlalu kecil untuk nomer benang $\mathrm{Ne}_{1} \quad 40$ yang menyebabkan mesin sering mati karena weft trouble.

2. Tekanan main nozzle dengan tekanan $0,33 \mathrm{Mpa}$

Pada tekanan 0,33 Mpa dengan menggunakan nomer benang $\mathrm{Ne} 1$ 40 dimana pada grafik percobaan dapat diliahat kejadian weft trouble adalah sekitar 42 kejadian hal ini bila dibandingkan dengan tekanan yang lain memiliki kejadian weft trouble yang sedikit hal ini karena tekanan 0,33 Mpa adalah tekanan yang cukup optimum bila dibandingkan dengan tekanan yang lain nya dengan weft trouble yang paling sedikit.

3. Tekanan main nozzle dengan tekanan 0,36 Mpa
Pada tekanan 0,36 Mpa dengan mengunakan nomer benang $\mathrm{Ne} 1$ 40 kejadian weft trouble mengalami kenaikan yaitu sekitar 57 kejadian bila dibandingkan dengan tekanan 0,33 Mpa pada tekanan 0,36 ini mengalami kenaikkan weft trouble hal ini karena tekanan terlalu besar sedangkan diameter benang yang dipakai termasuk diameter kecil hal ini karena ketika proses penyuapan benang pakan tekanan yang terlalu besar akan mengakibatkan benang keluar dari lintasan hal ini dikarenakan terjadinya fenomena turbulensi, fenomena turbulensi ini terjadi ketika tekanan terlalu besar pada proses penyuapan benang pakannya. Ketika proses penyuapan dengan tekanan udara terlalu besar meyebabkan benang mengalami fenomena turbulensi yang menyebabkan benang keluar dari jalurnya ditambah lagi dengan nomer benang yang digunakan relatif memiliki diameter yang lebih kecil hal ini mengakibatkan benang mengalami dorongan yang relatif lebih besar dan cenderung mudah keluar dari lintasan yang menyebabkan weft trouble, dari grafik hasil percobaan didapatkan tekanan 0,36 Mpa kejadian weft 
troubel mengalami peningkatan yaitu sebanyak 57 kejadian.

4. Tekanan main nozzle dengan tekanan 0,39 Mpa

Pada tekanan 0,39 Mpa dengan menggunakan nomer benang Ne1 40 dapat dilihat weft trouble yang terjadi yaitu sekitar 68 kejadian hal ini dapat dijelaskan karena benang menggunakan nomer benang yang memiliki diameter yang kecil sedangkan tekanan yang diberikan relatif besar yaitu sekitar 0,39 Mpa bila dibandingkan dengan tekanan sebelumnya yaitu tekanan 0,36 Mpa mengalami kenaikan weft trouble sebanyak 68 kali sedangkan tekanan 0,36 Mpa mengalami kejadian weft trouble sebanyak 57 kali kejadian. Hal ini dikarenakan tekanan udara

\subsection{Tekanan Udara Optimum} pada Beberapa Nomer yang Digunakan

Dari hasil percobaan diatas dengan mengunakan nomer benang $\mathrm{Ne} 120$, $\mathrm{Ne} 130$ dan $\mathrm{Ne} 140$ didapatkan grafik pada proses penyisipan benang pakan terlalu besar ketika tekanan udara tidak optimal atau terlalu besar benang akan cenderung keluar dari lintasan penyisipannya hal ini dikarenakan tekanan udara yang terlalu besar akan menyebabkan fenomena turbulensi yang menyebabkan benang keluar dari jalurnya ditambah lagi dengan nomer benang yang digunakan relatif memiliki diameter yang lebih kecil hal ini mengakibatkan benang mengalami dorongan yang relatif lebih besar dan cenderung mudah keluar dari lintasan, penambahan tekanan udara yang tidak sesuai dengan nomer benang menyebabkan mesin mengalami penambahan kejadian weft trouble yaitu sekitar sekitar 68 kejadian.

tekanan yang optimum yang dapat digunakan oleh perusahaan. Grafik ini didapat dari kesimpulan dari tekanan yang optimum dari masing-masing nomer benang terhadap weft touble selama satu shift yaitu dapat dilihat pada gambar 6 sebagai berikut ini. 


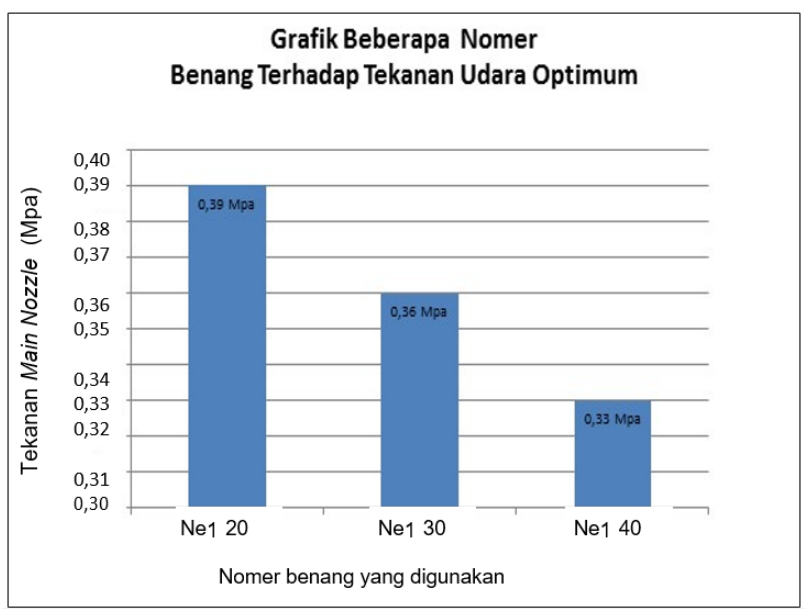

Gambar 6. Grafik Beberapa Nomer Benang Terhadap Tekanan Udara Optimum

Dari grafik tersebut dapat dilihat tekanan udara untuk nomer benang Ne1 40 optimumnya adalah mengunakan tekana udara 0,33 Mpa, sedangkan tekanan udara untuk nomer benang $\mathrm{Ne}_{1} 30$ mengunakan tekanan 0,36 Mpa, dan tekanan untuk nomer benang $\mathrm{Ne} 1 \quad 20$ mengunakan tekanan 0,39 Mpa. Hal ini sesuai dengan teori dimana semakin besar diameter pada nomer benang maka tekanan nya harus semakin besar. Dari hasil kesimpulan grafik bahwa benang dengan diameter besar (Ne1 Kecil) harus mengunakan tekanan udara yang relatif besar, begitupun sebaliknya benang yang diameter kecil (Ne1 Besar) harus mengunakan tekanan udara yang relatif lebih kecil. Hal ini dapat dijelaskan karena ketika benang dengan diameter besar pada saat peluncuran benang pakan tidak mendapatkan tekanan udara yang relatif besar maka benang akan kekurangan daya dorong oleh sebab itu harus mendapatkan udara yang besar, karenakan benang dengan diameter besar ketika proses penyisipan benang pakan diameter besar akan di dorong oleh tekanan udara pada permukaan kain yang menyebabkan pengaturan tekanan udara nya pun harus besar, jika mendapatkan tekanan terlalu rendah benang akan short pick (pakan tidak sampai).

Sedangkan benang dengan diameter kecil harus mendapatkan udara yang relatif lebih rendah karena jika benang mendapatkan udara yang besar benang akan mengalami long pick 
(pakan berlebih). Karena benang mengalami dorongan tekanan udara dari atas dan bawah dengan cara melingkupi permukaan benang dimana benang dengan diameter besar harus mendapatkan udara yang besar karena jika tidak mendapatkan tekanan udara yang sesuai untuk benang dengan diameter besar tidak akan sampai di ujung kain. Sedangkan benang dengan diameter kecil jika tekanan udara terlalu besar akan meyebabkan pakan berlebih oleh sebab itu tekanan udara harus relatif rebih rendah.

\section{KESIMPULAN}

Dari hasil pembahasan bab III dapat disimpulkan bahwa tekanan optimum main nozzle Pada AJL Tsudadkoma adalah :

- Untuk nomer benang $\mathrm{Ne}_{1} 20=0,39$

- Untuk nomer benang $\mathrm{Ne}_{1} 30=0,36$

- Untuk nomer benang $\mathrm{Ne}_{1} 40 \quad=0,33$

\section{DAFTAR PUSTAKA}

1. Adanur, Sabit (2009). Henbook of weaving. Switzerland ITEMA (Switzerland) Ltd.

2. Belforte, G .et (2009), Numeric model of an air jet loom main nozzle for drag force evaluation.Textile Research Journal.

3. Complete textile glossary (2001), Celanese Acetate LLC.

4. Duxubury et, (1959), A study some factor involved in pneumatic weft propulsion, Journal of The Textile Institute Proceedings.

5. Kurniawan, Ryan Hasan (2014), Pengamatan tentang penyetelan udara main nozzle pada proses pembuatan kain denim yang mengunakan pakan filament tekstur ditinjau dari kegagalan peluncuran pakan pada air jet loom Toyota, Sekolah Tinggi Teknologi Tekstil, Bandung.

6. Maintenance manual mechanical section, ZAX9100 Air jet Loom. 
7. Pian sarif Hidayat (2018), Studi Menentukan Tekanan Udara Pada Main Nozzle Mesin Tenun AJL Tsudakoma Type Zax 9100 Dengan Menggunakan Nomor Benang Yang Berbeda, Skripsi, Politeknik STTT, Bandung.

8. S. Lóránt and S. László, (2012), Weft insertion through open profile reed in air jet looms,International Journal of Engineering.

9. Somali, Andi (2014), Pengaruh penyetelan tekanan udara main nozzle dan sub nozzle terhadap weft stop pada pertenunan kain denim dengan mengunakan benang pakan tekstur reguler dan benang tekstur elastis di mesin air jet loom merek Toyota tipe JAT 610, Sekolah Tinggi Teknologi Tekstil, Bandung.

10. Sudjana, (2005),Metode Statistika Edisi 6,Tarsito, Bandung.

11. Utomo, Suseno (1988), Metoda Statistik untuk industri Tekstil, Sekolah Tinggi Teknologi Tekstil, Bandung 